\title{
Exogenous Factors in the Development of Flexible Fuel Cars as a Local Dominant Technology
}

\author{
Paulo Tromboni de Souza Nascimento, Abraham Sin Oih Yu, Robson Quinello, \\ Rosária de Fátima S. Macri Russo', Francisco Nigro², Nilton Cesar Lima'
}

\begin{abstract}
With flexible fuel technology, customers can choose gasoline, ethanol, or any mix thereof at the fuel station pump. This paper presents the endogenous and exogenous factors that influnced the development of a flexible fuel electronic injection system by Magneti Marelli Automotive Systems Brazil - the first to the market. This software-based architecture, launched commercially in 2003, is now the dominant flexfuel design in the Brazilian market. This article documents the emergence of a local dominant technology (design) in a specific car sub-system. It is shown how exogenous institutional factors played the major role in this process. The paper also shows that this local dominant technological design emerged through the sharing of capabilities and interaction among the key market players, in the absence of a strong appropriability regime. All the main market pioneers were multinational affiliates, inviting questions concerning this technology diffusion outside Brazil.
\end{abstract}

Keywords: automotive industry; biofuels; ethanol; local dominant design; power train technology.

\footnotetext{
I Administração e Contabilidade FEA, São Paulo, Brazil. Av. Prof. Luciano Gualberto 908 sl EI I I, Cidade Universitária, $05508-900$ - Sao Paulo, SP - Brasil. Phone: (55II) 309I5837. (Corresponding author) Email: tromboni@usp.br, Abraham.sinoih.yu@hotmail.com, rquinello@usp.br, rmrusso@usp.br, cesarlim@yahoo.com

2 Universidade de São Paulo - Escola Politécnica, São Paulo, Brazil. Phone: (55I I) 942078I0. Email: fnigro@usp.br
} 


\section{Introduction}

The automotive industry is present in nearly all continents; it directly and indirectly employs over 60 million people worldwide, and experienced $30 \%$ growth in the past decade. Developing countries have been experiencing a $16 \%$ increase rate per year. Brazil is currently the world's sixth largest manufacturer of motor vehicles (OICA, 2008). The industry is also directly responsible for $16 \%$ of carbon dioxide emissions, and interferes with daily life in aspects ranging from urban traffic to the use of rural areas. In 2007 alone, the auto industry invested 85 billion euros in R\&D geared at developing sustainable technology. It is searching new energy sources as alternatives for the current scenario of the intensive century-old economic use of gasoline and diesel, now being openly discouraged.

In the search for alternative engine energy sources, Brazil has developed one locally - ethanol. The Pró-álcool program (1975) provided the infrastructure and know-how that made the use of ethanol fuel possible. By the late 1980s, a combination of declining oil prices, increasing ethanol prices, and a decrease in fiscal incentives to ethanol fuel use led to the 1989-1990 ethanol shortage during the sugarcane off-season. The Brazilian government took action to keep the ethanol option alive. Several policies were implemented to encourage or force the use of ethanol-fueled cars, including the "green fleet" (all official government fleet vehicles had to be ethanolpowered) and fiscal incentives. However, this ethanol shortage led to mistrust among consumers.

In turn, this prompted the development of the flex fuel power train. The countrywide infrastructure for ethanol and gasoline distribution, already in place, allowed immediate adoption of flexible fuel cars by customers, after its launch in 2003 March. By 2008, as shown in Figure I, $91 \%$ of the new cars sold in Brazil were flexible-fuel vehicles (ANFAVEA, 2008), that is, capable of running on a mix of gasoline and ethanol in any proportion.

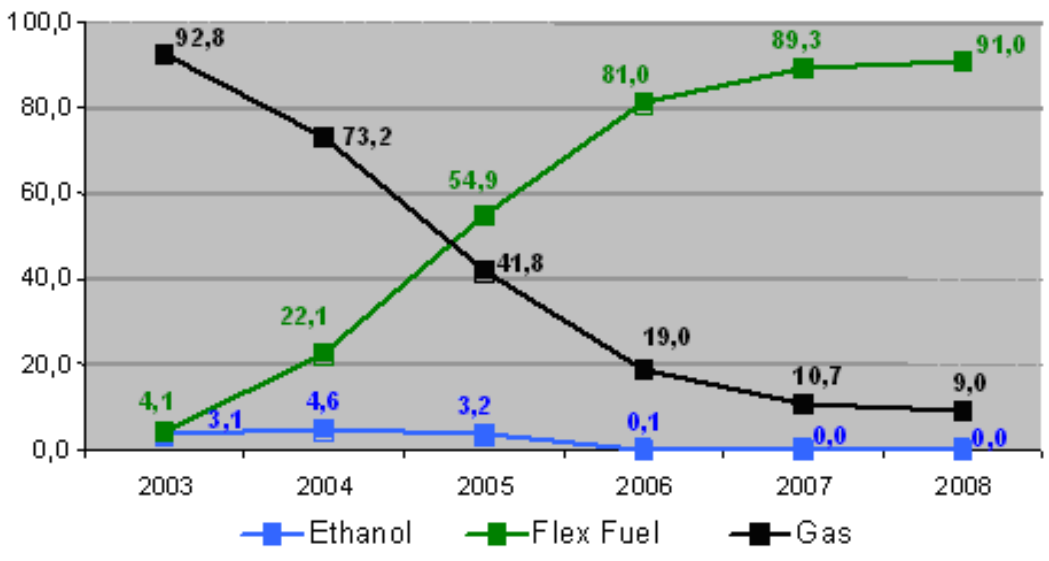

Figure I. Brazil fuel market share. Data from ANFAVEA (2008).

In this historical context, we conducted a case study on one of the first companies to launch the flex fuel technology: Magneti Marelli Sistemas Automotivos (MM), a supplier of electronic injection subsystems to local automakers. Which endogenous and exogenous factors led this company to stand out among others in the development of flexfuel technology in Brazil? With this research question in mind, we set out to identify these factors and assess their significance to the case subject.

\section{Research methods}

This study began in the second semester of 2008, at the University of São Paulo's graduate program. The professors of a discipline on Innovation Management went out in the field with their students, conducting interviews with key players in the development and deployment of this technology. $\mathrm{MM}^{5}$ together with Volkswagen Brazil launched the first flexfuel car in the Brazilian market. So

${ }^{5}$ Unless explicitly stated, throughout this paper MM denotes the Brasilian subsidiary of Magneti Marelli. 
this article reports on a single-case study and answers the general research question of which endogenous and exogenous factors facilitated the development of flexfuel technology in the company.

The case study is "the preferred strategy when [...] the investigator has little control over events, and when the focus is on a contemporary phenomenon within some reallife context" (Yin, 200I, PP. 23). While each single-case study is "a distinct experiment that stands on its own as an analytic unit", the case study as a method provides the advantage of emphasizing "the rich, real-world context" in which the studied phenomenon occurs (Eisenhardt and Graebner, 2007). We conducted two open interview sessions with a group of six MM professionals between September and November 2008. One interview was dedicated to Volkswagen and ANFAVEA - the automakers trade association - (the same respondent for both). Five other interviews were conducted, with two MM competitors, another automaker, and a former executive of UNICA, the ethanol producers' trade association.

\section{The flexible fuel technology}

Ethanol supports a higher compression ratio than gasoline, substitutes for anti knocking additives, and requires new anti corrosion materials. It also requires differing spark timing and higher volume injection, as well as a different air fuel mix. And its pollutant emission properties also differ significantly from those of gasoline. Of course, differing calibrations are also needed for differing proportions in a given mix of ethanol and gasoline.

By the end of the 1980s, flexfuel technology developed by Bosch was already available in the United States. This early technology used a capacitive sensor placed at the fuel intake. In the 1990s, Bosch attempted to bring its technology to Brazil, but was unsuccessful.

Several interrelated technical changes are required at the engine and power train to make the car able to run on ethanol or even on a stable mix of ethanol and gasoline. For this, lots of components and subsystem technical changes are required, and several suppliers are involved. For flexible fuel cars the critical part has proved to be the fuel injection and ignition subsystem. It no longer has a stable calibration. Instead, this subsystem must provide a calibration adjusted to the proportion of ethanol and gasoline in the fuel. This proportion may suddenly change at the driver discretion, whenever he or she chooses the fuel, at the pump.

The innovation hereby examined seems to follow an evolutionary and cyclic model of technological change (Anderson and Tushman, 1990). Incorporated into a power train, this technology then supports the stablishment of a dominant design: the flex fuel vehicle (the platform).

Looking ahead, the auto industry research is focusing on the development of more efficient powertrains coupled with the use of renewable fuels, locally obtainable ones if possible (Rozen, 2007). The companies are also fiercely competing to be the first to launch a fuel cell-powered vehicle, but this technology seems to be still over a decade away from a performance competitive with internal combustion engines. Rozen (2007) also assess that hydrogen-powered electric vehicles will make it to the market, but no sooner than 2022, due to the technology embryonic stage. Even if hydrogen eventually becomes the dominant automotive fuel, other technologies are expected to play a transitional role. This transitional technology may be biofuel, of which ethanol is the prime element, followed by biodiesel.

Flex fuel is a new technology, at the beginning of its $S$ curve. Although not reviewed here there are a lot of possible improvements ahead. So it is early to know how it will fare. But it must have good prospects since hybrid cars - the only current commercial alternative powertrain can also be powered by a flex fuel engine.

\section{The development of flex fuel technology at MM}

MM is part of the Magneti Marelli Group, an Italian company that operates 46 production plants, 9 R\&D centers (including one in Brazil) and 27 "Application Centres" in 16 countries worldwide, producing high-tech solutions for the automotive sector (MM, 2009). MM is responsible for the development, manufacturing, and sale of fuel injection engine control, and transmission systems and components. By the end of the 90's, MM's global strategy included encouraging software-based solutions, in order to decrease costs, although technical controversies still surrounded this approach (Castro, et al., 1994) concerning the flexfuel subsystem. 
By 1999, MM was in dealings with an automaker to provide technology for an ethanol-fueled car when it was notified that the program was being terminated. As the Brazilian branch believed in ethanol, the company began informal work that led to the Software Fuel Sensor (SFS) system. An in-house group began development of the software, which had been created by an internal innovation program. The group faced three challenges: i) recognizing fuel mix in the tank without the need for a specific sensor: by processing information avaiable from other sensors, ii) re-adapt engine parameters according to the ratio of ethanol to gasoline; this is the greatest challenge. iii) ensuring driver comfort, driver and passenger safety, environmental commitment, and the service life of the engine.

MM then developed the flexfuel technology, in an improvised manner, as in the front end of development (Murphy and Kumar, 1997). In fact, the first experiments were conducted by an Italian engineer who had come to Brazil in order to assist in the electronic fuel injection solutions deployment. This engineer conducted these experiments in his spare time, on his private car. His choice of vehicle is easily explained: the Polo's ECU had been developed by MM (IAVP) involving a mature technology, making much easier the needed software changes. At this stage, results were constantly reported to the MM development team, and even to the company president. Thus, the experiments were kind of "unofficial official" ones.

In 2000, MM attempted to conduct a few tests with a rented car, but gave up the attempet, as there was no way to return the vehicle to its original condition. In parallel, MM began talks with automakers about their flexfuel solution, but there was no interest in developing the concept. At the time, there was no dedicated flexfuel project in the company.

In 200I, MM finally bought a test vehicle for further experimentation. And in the following year, VW sent a set of 15 questions, as a way of assessing the robustness of MM's proposed software-based bi-fuel solution. The MM believes their answers were a determining factor in VW's decision to accept the MM solution and implement it as an in-house project.

The software (consisting of 100,000 lines of code, integrated to the electronic fuel injection system) receives input from several sensors, the most important of which is the lambda probe - although, if it stops working, the car keeps running at lower performance. This probe measures the exhaust oxygen content for environmental control purposes and is already a part of the vehicle's standard equipment, avoiding new costs.

Usually, technological development at MM is carried out in its Italian headquarters, which develop a base product that can be modified and applied where needed. Participation from other countries amounted to around 15\% of the project's efforts, and is geared specifically at system integration. The flex fuel development nonetheless was a Brazilian led effort and took around three years and a 30 people team, and amounted to around US $\$ 10$ millions, most of which was spent on salaries: almost the entire software required adaptation, because fixed fuel composition parameters became functions of several variables. Integration of technological development was accomplished through the proactivity of all team members, expressed as a daily exchange of information, experience, and discussion on current developments.

MM made some marketing push on its flexfuel program, through meetings with stakeholders: sugarcane growers and alcohol producers, the government, distributors, automakers, universities, the media, and Petrobras.

$M M$ is a subsidiary of Fiat, but it maintains relations with all other automakers. At the time, the company had two major clients: Fiat and Volkswagen. The deal between Volks and Marelli was closed by mid 2002, and the first flexfuel car using MM technology was launched by Volks on March 24, 2003. The next flexfuel car to reach the Brazilian market, in September 2003, used Delphi technology. Despite its efforts in the early 90's, Bosch was only the third large local system provider to deploy software based flexfuel technology.

MM currently has $42 \%$ share of the global market of flex and non-flex products. Before the development of flex technology, its share was $39 \%$ and $47 \%$ share of the flexfuel technology market, while Bosch holds $24 \%$, and Delphi has 18\%. MM Brasil also became a platform for the development of new technologies in the group, and it is the group's second largest unit, surpassed only by MM's Italian headquarters. Strategically, Marelli reinvests around $10 \%$ of its $\mathrm{R} \$ 500$ million yearly revenue on new technology and equipment. Hybrid vehicles are now being studied as a more modern market for possible 
advances in new technology solutions. MM currently employs 160 people in its R\&D facility in Hortolândia, São Paulo.

Suarez (2004) has shown the connections in the literature concerning dominant design, dominant technology and related concepts, suggesting that they reveal different stages on a larger process of competitive struggles. Suarez (2004) also listed factors to explain the result of a battle for technological dominance. Using the work of several authors (Brown and Eisenhardt, 1995; Hill and Rothaermel, 2003; Krishnan and Ulrich, 200I; Suarez, 2004) as a foundation, we identified 9 endogenous and 7 exogenous factors whose impact on the process of flexfuel technology generation at MM Brazil will be analyzed and theoretically discussed.

\section{Endogenous factors}

\section{Technological Superiority}

Suarez (2004) portrays technological superiority as an effort that, over time, can affect the result of a battle for technological dominance. To Krishnan and Ulrich (200I), these perspectives involve creative product development concept and configuration across marketing, engineering, management, and operations management, able to generate an innovative product that meets market needs. Hill and Rothaermel (2003) consider decision making surrounding investment in technology and its respective realization prospects to be a key point.

The main reason for the dominance in the current Brazilian market by the software-based solution introduced by $M M$ is the fact that it does not introduce any new parts to the engine assembly process, and therefore meets the ongoing demand for rationalization of manufacturing processes in the auto industry, particularly regarding costs. Orsato and Wells (2007) have characterized this demand as a continuous search. Nowadays, all suppliers use software-based systems.

\section{Credibility and complementary assets}

A company's production capacity and its reputation in the market may provide a measure of comfort to the buyers of a new technology (Suarez, 2004). MM was the Brazilian market leader in its sector (and still is) and the company undertook a significant effort to provide technical credibility to its technology, particularly through strong interaction with Volkswagen engineering. But there was no need to attract new talent.

\section{Installed base}

Launching a new product without having a definite installed base leads to higher costs for clients (Suarez, 2004). The commercialization of the new technology will also benefit from complementary assets (Hill and Rothaermel, 2003). MM had enough installed base of electronic injection equipment on its clients (such as Volkswagen and Fiat) cars and the flexfuel software resides in this subsystem. After all, it was the Brazilian market leader.

\section{Timing}

Hill and Rothaermel (2003) claim that the gestation period demarcates technological maturity. Srinivasan, Lilien, and Rangaswamy (2006) agree, stating that the time of emergence is responsible for market characteristics, the product's cost-effectiveness, the definition of standards, and breakthrough innovation. Brown and Eisenhardt (1995) link this factor to the skill of the project leader and to the organization itself.

The fuel injection system is customized by the supplier for each type of vehicle; MM therefore suffered from product gestation time restrictions imposed by automakers. An integrated and systemic approach to decision making is even more important in this factor, so that time to delivery may already be a product differentiation characteristic during development (Brown and Eisenhardt, 1995; Krishnan and Ulrich, 200I; Suarez, 2004). But in this case it was not a major difference among competitors.

\section{Pricing}

To Suarez (2004) pricing concerns strategic action. Krishnan and Ulrich (200I) postulates that pricing and product positioning are both relevant. Low product unit cost and slim profit margins are characteristic of the automotive industry (Orsato and Wells, 2007); deployment of the SFS software, which added no components to vehicles or to the production chain, therefore provided automakers with a major advantage over the use of the capacitive sensor-based technology. 


\section{Licensing and patent policies}

One important decision is the organization's policy on licensing technology or leaving it "open" for competitors to use (Suarez, 2004). MM decided to patent the SFS, but this does not seem to have provided a competitive advantage, as MM's competitors followed suit by launching similar products almost immediately.

\section{Marketing and public relations}

Marketing and public relations aim to manage the expectations of clients and all those involved in the new product launch (Suarez, 2004). Schilling (1998) also notes that suppliers and distributors may be invited to interact with development of a technology in order to avoid a possible technological lockout. Networks of specialized suppliers are increasingly considered to be factors that can facilitate management of breakthrough technological innovation (Meijer, Hekkert, Koppenjan, 2007).

MM was faced with a significant challenge in its attempt to develop opinion setters; it constantly promoted events and demonstrations with modified vehicles among stakeholders: sugarcane growers and alcohol producers, the government, distributors, automakers, and even Petrobras. Many of these players were quite reticent at first, such as alcohol producers, who did not like the idea of consumers being able to choose between their fuel and others. MM needed to interface with all stakeholders to break down such barriers, including automakers'.

\section{Team}

The organization and makeup of work teams has a direct effect on the performance of the product development process, as does team leader behavior (Krishnan and Ulrich, 200I; Brown and Eisenhardt, 1995). It is therefore important that the organization's values and rules legitimize any autonomous employee actions (Hill and Rothaermel, 2003).

As a leading player in flexfuel technology, MM Brazil had the task of adapting the company's electronic fuel injection systems to the usage conditions found in the Brazilian market, a process known as tropicalization. This Process served as an incubator for a group of R\&D engineers who ultimately worked on the 4AVP ECU, which was deployed in the first Brazilian flexible-fuel vehicle in 2003.

\section{Top Management}

Organizational alignment is absolutely paramount during product development (Kaplan, et al., 2003; Krishnan and Ulrich, 200I); economic success is the consequence of a series of co-factors in alignment: strategy, planning, product adequacy, projects, resources, and technology. As organizations become increasingly interdependent, so do their decisions become more complex, which creates the need for a systemic view from top management so that the functional aspects of development may be aligned (Krishnan and Ulrich, 200I) as the capacity to support and control the development process (Brown and Eisenhardt, 1995). At MM, we noted significant involvement of the company's directors and president, not only in the provision of support and autonomy to the development team, but also in the effort to convince stakeholders of the credibility of software-based flexfuel technology. The greatest enthusiast was a MM's former president, who took part in every stage of the technology development process and, particularly, in the extensive interaction with other stakeholders in the process. It bears noting that the organizational strategy of MM Italian headquarters allowed the company's Brazilian branch to develop a new technological alternative and provided support as necessary.

\section{Exogenous factors}

\section{Regulation}

The implementation of public policy can revolutionize an entire production chain, directly or indirectly defining a dominant technology through the use of restrictions, incentives, and even purchasing power (Suarez, 2004). The Brazilian government reduced taxes on ethanol and flexfuel cars. The São Paulo state's tax on ethanol was also reduced to half its value. São Paulo is the country's top sugarcane producer (around 2/3).

In 2002, the sugarcane industry was going through a crisis. Production of ethanol-powered cars in Brazil was practically at a standstill, and the government pressured for a solution. Stagnation in the sugar and ethanol industry was making it of no economic interest to sugarcane-producing states, and was also placing countless jobs on the line. This led to heavy pressure on local governments, particularly in the state of São Paulo. 
In Brazil, all new vehicle and engine models, whether domestic or imported, are required to receive emissions certification from CETESB (Companhia de Tecnologia de Saneamento Ambiental), which is charged by IBAMA (the Brazilian Institute of Environment and Renewable Natural Resources). MM played an active role in convincing the Brazilian government to match the taxes on flexfuel cars to that of solely ethanol-powered ones, and also lobbied for certification in order to make the launch of flexfuel vehicles possible.

\section{Network Effects}

Suarez (2004) defines network effects as direct - in which the greater the number of users of a certain technology, the greater the connection between them - and indirect, such as services and products derived from the technology. This factor also includes switching costs. In the automotive industry, economies of scale and entry cost are preponderant factors. The technology advocated did not require significant assembly lines changes from the automakers. Furthermore, it made use of the country's entire infrastructure of ethanol-capable fueling stations, giving consumers the possibility of swithcing from gasoline to ethanol as they find it convenient in terms of cost and performance.

\section{Regime of Appropriability}

An organization's regime of appropriability consists of its capacity to capture innovation-associated revenue, preventing competitors from using the technological innovation or at least slowing them down (Suarez, 2004). In the case of MM, despite holding the patent to SFS, it was unable to prevent competitor deployment of similar technologies.

\section{Competitors}

Successful implementation of a new technology requires great skill in forging agreements with other players for the production of goods and services (Suarez, 2004). Certain characteristics of the auto industry, such as market saturation and plant overcapacity (Orsato and Wells, 2007), provide automakers with conditions for having more than one supplier for each auto part, establishing a competitiveness that leads to flexibility in production and ever-decreasing costs. According to Volkswagen, when it started weighing the introduction of flexfuel engines, it requested alternatives to both $M M$ and Bosch. At automakers, engineers from several suppliers remain present during the new model development process, which leads to extensive information exchange. Intense employee turnover in the industry also contributes to information exchange.

\section{Suppliers}

A company's supply chain - its choice of suppliers and materials, its relationship with partners, and its contractual relationships - may be crucial to the dominance of technology (Krishnan and Ulrich, 200I). Hence, Brown and Eisenhardt (1995) stress the importance of supplier involvement in new product development. In this particular case of flexfuel technology, MM's suppliers did not play a relevant role in development, as there was no change in the MM supply chain.

\section{Clients}

Ford and General Motors had both undertaken efforts to develop flexfuel vehicle programs, using alcohol as an alternative fuel. In 2002, Ford exhibited a flexfuel prototype vehicle, based on Bosch technology, with a major impact on the popular press. This led other automakers to speed up their development. At the time, Volkswagen and FIAT were MM clients. Both makers bought the idea, and Volkswagen was the first to employ the new technology, in 2003. They were almost imediately followed by the major and older Brazilian automakers.

\section{End users}

Consumers were faced with a difficult situation: if, on the one hand, rising oil prices were driving up the cost of gas, on the other hand, car owners had lost faith in the government's alcohol fuel program after the 1989-1990 ethanol shortage during the sugarcane off-season. The possibility of choosing which fuel one wishes to use right at the pump became a runaway sales success, shown in Figure $\mathrm{I}$, as consumers recognized the added functionality of flexfuel technology and its economic and environmental benefits. The prime benefit is the possibility of profiting from the relative cheapness of ethanol in the domestic market, with the occasional exception of the off season, without running the risk of a new shortage. In addition, it is cheaper to buy flex fuel cars, due to governmental incentives through lower taxes. According to Alves (2007), 
MM's flexfuel technology also offers the benefit of decreased pollution, through the gas comsumption reduction.

End-user involvement in the solution, suggested by Brown and Eisenhardt (1995), occurred mostly at the aftermarket stage, during which $M M$ and its development team provided support to several Volkswagen dealerships to quickly solve any problems detected with the new technology.

\section{Some remarks and implications}

Figure 2 seeks to summarize the influence of the above factors, ranked on a three point grading scale $(+)$. If our ranking have been well done, exogenous factors clearly have had the greatest impact on this "technology battle". Anyway, this is also strongly suggested by the fast adoption by end users as well as automakers (Figure I). Stronger corroboration would require more research.

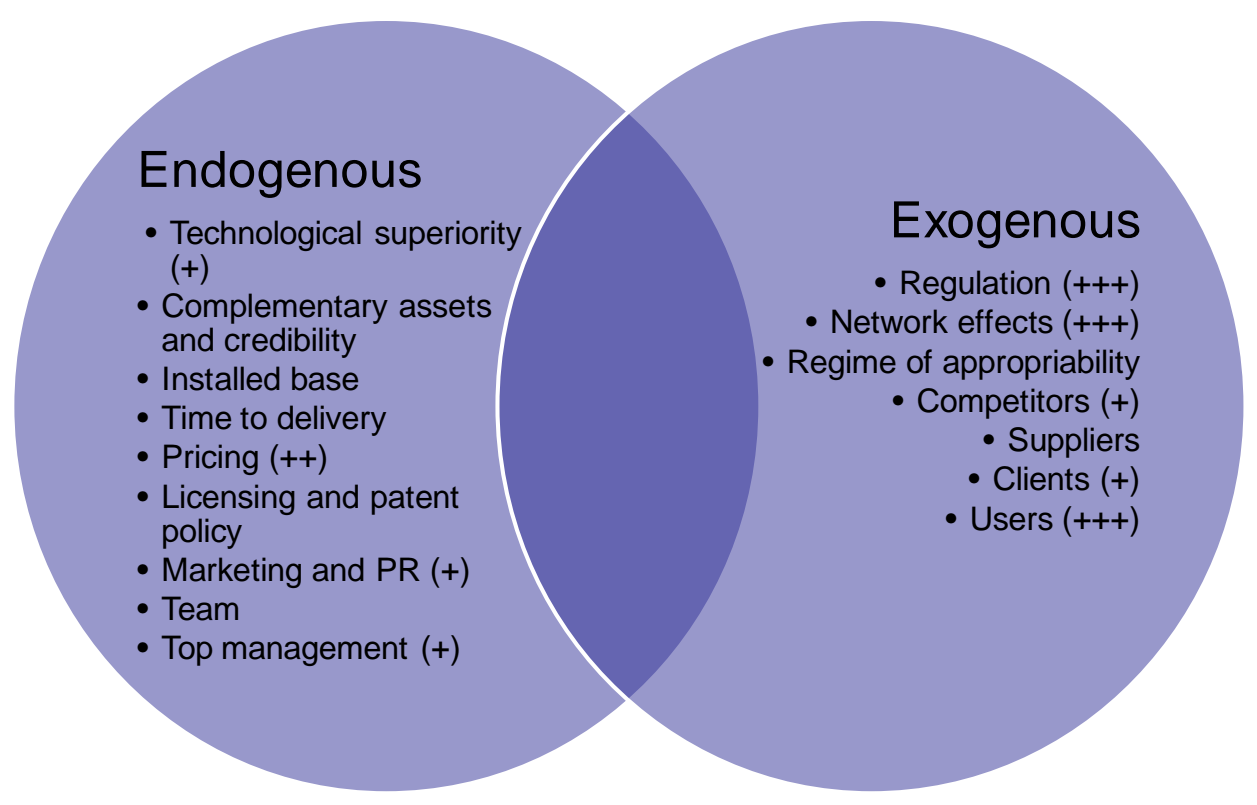

Figure 2. Brazil Influence of endogenous and exogenous factors in the MM case.

This particular "technology battle" (Suarez, 2004) was characterized by high turnover of employees between companies and participation of governments and trade associations. Competency sharing, quite removed from the notion of core competencies, is another contribution requiring more in-depth study; we found that the influence of the network of actors to have significantly homogenized not only knowledge but also gains - after all, MM's competitors very soon brought their own versions to the market.

The prevalence of exogenous institutional forces led to local alternatives. That is, vehicle fuel technologies or subsystems that may be regionally rather than globally dominant, each with its own specific technological trajectory (Dosi, 1982). Beise (2004) actually notes that globally dominant technologies originate at the regional level, and gain momentum in domestic environments before transcending borders. Here, we add that it is possible to conceive of simultaneously differing regional dominant technologies. Although this idea lacks in-depth empirical foundations, our case at least suggests the need for further study.

Another intriguing finding is the possibility of a combination of a global dominant design at the platform level with a local one at the power train level. This sheds light on the need to better understand the complex inter relations of shared competencies at the global and local level and begs for a better understanding of the factors involved. 
In spite of globalization, exogenous factors differ markedly on a geographical basis. Local automakers maintain strong ties with their headquarters, which do not always consider adequate their Brazilian branches proposed innovations. Even Volkswagen, which pioneered the launch of flexfuel technology, has had no support from its German parent to introduce it in Europe. France has halted its flexfuel program. In the United States, flexfuel vehicles may run on straight gasoline, E85, or a mixture of both, but most are still based on Bosch's specific sensor technology. On the other hand, Brazil is currently a platform for MM's alternative fuel solutions, and automakers and suppliers alike have benefited from the success of this technology, as their R\&D centers have grown and become bio fuel competency centers.

This, in turn, may explain the unexpexted role of the Brazilian multinational affiliates that led the creation of a global power train alternative. It is too early to know its global level impacts, but it already seems clear that the parent companies did not see this coming.

As a management implication, we found a need for closer attention to exogenous institutional factors. Closer relationships must be established and kept with institutional agents such as governments, the media, academia, technical institutions, and trade associations. These politically-oriented strategies seems to be required not only to achieve regional technological dominance, but are also critical to ensure its survival.

\section{References}

ALVES, M. de L. (2007). Carro Flex Fuel: uma avaliação por opções reais. Master's Dissertation. Pontifical Catholic University of Rio de Janeiro, Rio de Janeiro, $94 \mathrm{f}$.

ANDERSON, P., Tushman, M.L. (1990). Technological discontinuities and dominant designs: a cyclical model of technological change. Administrative Science Quartely, 35, 604-633.

ANFAVEA - Associação Nacional dos Fabricantes de Veículos Automotores (2008). http://www.anfavea.com.br [Retrieved from the Web 08/22/2008]

BEISE, M. (2004) Lead markets: country-specific drivers of the global diffusion of innovations. Research Policy, 33, 9971018.
BROWN, S. L., Eisenhardt K. M. (1995) Product development - past research, present findings, and future directions. Academy of Management Review, 20 (2), 343378.

CASTRO, A. C., Korter C. H, Franieck E. K. (1994). Flexible ethanol otto engine management system, in Papers presented at III Congresso e Exposição Internacionais de Tecnologia da Mobilidade - SAE Brasil [CD-ROM], São Paulo.

DOSI, G. (1982). Technological Paradigms and Trajectories. Research Policy, II, 147-162.

EISENHARDT, K.M., Graebner, M.E. (2007). Theory building from cases: opportunities and challenges, Academy of Management Journal, 50 (I), 25-32.

HILL, C. W. L., Rothaermel F. T. (2003). The performance of incumbent firms in the face of radical technological innovation. Academy of Management Review, 28 (2), 257274.

KAPLAN, S., F. Murray, R. Henderson (2003). Discontinuities and senior management: assessing the role of recognition in pharmaceutical firm response to biotechnology. Industrial and Corporate Change, 12 (4), 203233.

KRISHNAN, V., Ulrich K. T. (200I). Product development decisions: A review of the literature. Management Science, 47 (I), I-2I.

MEIJER, I. S. M., Hekkert M. P., Koppenjan J.F.M. (2007). How perceived uncertainties influence transitions; the case of micro-CHP in the Netherlands. Technological Forecasting and Social Change, 74 (4), 519-537.

MM - Magneti Marelli Sistemas Automotivos (2009). http://www.magnetimarelli.com/english/il_gruppo.php

[Retrieved from the Web 0I/26/2009]

MURPHY, S. A.; Kumar, V. (1997) The Front End of New Product Development: a Canadian Survey. R\&D Management, 27 (I), 5-15.

OICA - Organisation Internationale des Constructeurs d'Automobiles (2008). http://www.oica.net/ [Retrieved from the Web II/I0/2008]

ISSN: 07I 8-2724. (http://www.jotmi.org)

Journal of Technology Management \& Innovation (C) Universidad Alberto Hurtado, Facultad de Economía y Negocios 
ORSATO, R. J., Wells, P. (2007), U-turn: the rise and demise of the automobile industry. Journal of Cleaner Production, I5 (II-12), 994-I006.

ROZEN, M. (2007). O Einstein automotivo, AUTODATA, n. I5, special edition, I2-18.

SCHILLING, M. A. (1998). Technological lockout: An integrative model of the economic and strategic factors driving technology success and failure. Academy of Management Review, 23 (2), 267-284.

SRINIVASAN, R., Lilien G. L.,Rangaswamy A. (2006). The emergence of dominant designs. Journal of Marketing, 70 (2), I-I7.

SUAREZ, F. F. (2004). Battles for technological dominance: an integrative framework. Research Policy, 33, 27I-286.

YIN, R. K. (200I). Estudo de Caso: Planejamento e Métodos. Rio de Janeiro: Bookman. 